thuốc khi huyết cao hay chỉ uống khi có dấu hiệu của THA (đau đâu, chóng mặt, hoa mắt...).

\section{KẾT LUÂ̂N}

1. Thực trạng giáo dục sức khỏe cho người bệnh tăng huyết áp tại bệnh viện Trường đại học Y khoa Vinh năm 2020

- 100\% người bệnh tăng huyết áp được nhân viên y tế giáo dục sức khỏe với tư vấn cá nhân $(80 \%)$ và tài liệu phát tay $(72 \%)$.

- 70,4\% người bệnh được tư vấn, giáo dục sức khỏe phù hợp với bệnh khi vào viện, trong quá trình điêuu trị và lúc ra viện

- 81,5\% nhân viên đánh giá bệnh viện không tiến hành đánh giá (hoặc nghiên cứu) hiệu quả hoạt động truyên thông, giáo dục sức khỏe cho người bệnh.

2. Hiệu quả chương trình giáo dục sức khỏe cho người bệnh tăng huyết áp tại bệnh viện Trường đại học $Y$ khoa Vinh

- Đa số người bệnh có kiến thức về bệnh THA như biểu hiện, trị số huyết áp, thời điểm đo huyết áp bệnh THA

- 72\% người bệnh có kiến thức về nguyên tắc điều trị THA là điều trị lâu dài,

- Chỉ có 4\% người bệnh không biết nguyên tắc điều trị của bệnh THA

- 90\% người bệnh THA có kiến thức tái khám theo lịch hẹn

TÀI LIẸU THAM KHẢO

1. Hội tim mạch Việt Nam (2018), "Khuyến cáo về chẩn đoán điều trị \& dư phòng THA". Trang web http://vnha.org.vn/data/Khuyen-Cao-THA-2018, truy câp ngày 20/3/2020

2. Cục y tế dự phòng, Bộ Y tế (2015), "THA, kẻ giết người thiâm lă̆ng"

3. Tan Van Bui, Christopher Leigh Blizzard., Khue Ngoc Luong, Ngoc Le Van Truong, Bao Quoc Tran, Petr Otahal, Mark R.Nelson Seana Gall. and and at el (2016), "National survey of risk factors for noncommunicable disease in Vietnam: prevalence estimates and an assessment of their validity", BMC Public Health, Volume 16, pp.489.

4. Nguyễn Thái Quỳnh Chi (2018) tạp chí khoa học tập 3 số 2-2019. Đánh giá việc thực hiên nhiệm vụ tư vấn, hướng dẫn GDSK cho bênh nhẩn Khoa Nội Tim mạch-Lão học, Bệnh viện đa khoa tỉnh Khánh Hòa năm 2018

5. Trương Thị Thùy Dương (2016) Hiêuu quả của mô hình truyền thông giáo dục dinh dưỡng nhằm cải thiên môt số yếu tố nguy cớ THA tai công đồng

6. Trân Thị Hằng Nga (2018), "đánh giá hoạt động GDSK của người điều dưỡng bệnh viện đa khoa tỉnh Quảng Trị và một số yếu tố liên quan, năm 2018", Khoa học điều dưỡng tập 1 (số 3 2018)

7. Carlo Marra., Karissa Johnston. and Valerie Santschi (2017), "Cost-effectiveness of pharmacist care for managing hypertension in Canada", Canada Pharmacists Jounal, Volum 150(3), pp.184-197.

\title{
KẾT QUẢ PHẪU THUÂT ĐÎ̀̂U TRI BONG VÕNG MẠC CO KÉO DO ĐÁI THÁO ĐƯờNG CÓ SỬ DỤNG PFCL
}

\section{TÓM TẮT.}

Mục tiêu: đánh giá kết quả phẫu thuật điều trị bong võng mạc co kéo do đái tháo đường (ĐTĐ) có sử dụng dung dịch Perfluorocarbon (PFCL). Đối tượng và phương pháp nghiên cứu: nghiên cứu can thiệp lâm sàng không đối chứngtrên 21 bệnh nhân (21 mắt) bị bong võng mạc co kéo do ĐTĐ. Kết quả: tại thời điểm 3 tháng sau phẫu thuật, tỷ lệ võng mạc áp là95,2\% (20/21 ca) thị lực cải thiện so với trước mổ có ý nghĩa thống kê $p<0,001$; các biến chứng gặp sau mổ là: tăng nhãn áp sau 2 ngày $2 \mathrm{ca}$, xuất huyết dịch kính: 2ca, 1 ca xuất hiện màng trước võng mạc. Có sự

\footnotetext{
${ }^{1}$ Trường Đại học Y Hà Nội

²Bênh viện Mắt Trung Ương

Chịu trách nhiệm chính: Vũ Tuấn Anh

Email: vta.oph@gmail.com

Ngày nhận bài: 11.8 .2021

Ngày phản biện khoa học: 5.10.2021

Ngày duyệt bài: 14.10.2021
}

Trần Đăng Quang ${ }^{1}$, Vũ Tuấn Anh ${ }^{2}$

khác biệt về kết quả phục hồi về giải phẫu và chức năng giữa nhóm bong qua hoàng điểm và chưa qua hoàng điểm. Kết luận: phẫu thuật cắt dịch kính điêu trị bong võng mạc co kéo do ĐTĐ có sử dụng PFLC giải phóng mù lòa và khắc phục được biến chứng giai đoạn cuối, nhằm cứu vãn thị lực dù còn thấp cho bệnh nhẩn ĐTĐ biến chứng

Tư khóa: bong võng mạc co kéo do ĐTĐ, cắt dịch kính, PFCL

\section{SUMMARY \\ RESULTS OF VITRECTOMY USING PFCL FOR TREATMENT OF DIABETIC \\ TRACTIONALRETINAL DETACHMENT}

Aims: results of surgery using PFCL for treatment ofdiabetictractional retinal detachment. Methods: interventional cases series. Patients received an Avastinintravitreal injection prior to undergoing vitrectomy to remove hemorrhage, traction and reattach the retina. Results: for 21 cases, results 3 months after surgery: $95,2 \%$ of cases retinal re- 
attached (20/21), visual recovery. Complications as high IOP, vitreous hemorrhage, secondảy epiretinal membrane. Conclusion: vitrectomy using PFCL for treatment ofdiabetic tractional retinal detachment have good outcomes for anatomical and visual recovery,prevent blindness and savevision for patients with complicated diabetic.

Keywords: diabetic tractional retinal detachment, vitrectomy, PFCL

\section{I. ĐĂT VẤN ĐỀ}

Bong võng mac (BVM) co kéo là biến chứng nặng của bệnh võng mạc đái tháo đường (ĐTĐ) giai đoạn tăng sinh, có nguy cơ đe dọa mất thị lực đứng hàng đầu. Tỷ lệ mắc bệnh có xu hướng ngày càng tăng tuy nhiên điều trị BVM co kéo cho đến nay vẫn còn là thách thức trong nhãn khoa.

Phẫu thuât cắt dich kính điều trị BVM co kéo do bênh ĐTĐ̇ đòi hỏi phải loại bỏ tối đa các co kéo dịch kính võng mac tạo điều kiện cho võng mạc áp trở lại.Cùng với nghiên cứu sự tiến bộ về kỹ thuật và ứng dụng các chất liệu dùng trong phẫu thuât đặc biêt là dung dịch perfluorocarbon (PFCL) đã đem laai những tiến bộ vượt bậc trong điều trị BVM. Trên thế giới, năm 1982 Haidt đã thử nghiệm PFCL như là một chất độn trong buồng dịch kính, năm 1987 Chang và cộng sự đã sử dụng $\mathrm{PFCL}$ trong phẫu thuật dịch kính trên bệnh nhân BVM có tăng sinh dịch kính võng mạc trầm trọng ${ }^{1,2}$. Nhờ các đặc tính đặc biệt kể trên, PFCL có ưu điểm rất lớn trong việc giữ cố định võng mạc trong quá trình cắt dịch kính, trải phẳng các nếp gấp và vùng võng mạc bong, qua đó bóc tách các màng tăng sinh, giải phóng co kéo trước-sau và co kéo ngang dễ dàng hơn, tháo dịch dưới võng mạc tránh phải mở võng mạc vùng hậu cực, giảm năng lượng laser khi quang đông toàn võng mạc, do đó rút ngắn thời gian phẫu thuật và đem lại kết quả cao trong điều trị BVM co kéo. Tuy nhiên chưa có nghiên cứu nào đánh giá về kết quả của can thiệp này ở Việt Nam. Vì vầy chúng tôi tiến hành nghiên cứu: "Phẫu thuâtt cằt dịch kính điều tri bong vông mạc co kéo do đái tháo đường có sừ dụng dung dịch perfluorocarbon"

\section{II. ĐỐI TƯỢNG VÀ PHƯƠNG PHÁP NGHIÊN CỨU}

Nghiên cứu được tiến hành trên nhóm bênh nhân bi BVM co kéo do ĐTĐ có chỉ định phẫu thuật tại Bệnh viện mắt TW từ tháng $8 / 2020$ đến tháng $5 / 2021$.

Tiêu chuẩn lựa chơn bênh nhân: bênh nhân bị BVM co kéo do ĐTĐ, có chỉ định phẫu thuật cắt dịch kính

Thiêt kế nghiên cứu: nghiên cứu can thiệp lâm sàng không đối chứng, cỡ mẫu là21bệnh nhân. Số liệu được xử lý và phân tích bằng chương trình thống kê SPSS 16.

Các bước tiến hành nghiên cứu. Bệnh nhân BVM co kéo do ĐTĐ nhập viện được khám, làm hồ sơ bệnh án, đo thị lực nhìn xa với kính và không kính, đo nhãn áp, đánh giá tình trạng giác mạc, thủy tinh thể, khám đáy mắt bằng kính 3 mặt gương Goldmann hoặc đèn soi Schepens kết hợp kính + 20D đánh giá tình trạngBVM, dịch kính, vị trí - số lượng - đặc điểm tăng sinh co kéo...

Tiêm Avastin liều $1,25 \mathrm{mg} / 0,05 \mathrm{ml}$ vào buồng dịch kính trước phẫu thuật 5-7 ngày

Quy trình phẫu thuật: bệnh nhân được gây tê cạnh nhãn cầu, với những trường hợp còn thủy tinh thể (TTT) có chỉ định phẫu thuật thay TTT kèm theo cắt dịch kính. Dùng đầu cắt $23 \mathrm{G}$ cắt dịch kính từ trung tâm ra ngoại biên. Bớm từ từ vào nội nhãn $1 \mathrm{ml}$ đến $5 \mathrm{ml}$ dung dịch $\mathrm{F}$ Decalin, bắt đầu từ vùng gai thị, kỹ thuật bơm 1 bóng $\mathrm{F}$ - Decalin sao cho dung dịch trải đều vùng võng mạc hậu cực, tránh làm vỡ thành nhiều giọt nhỏ, chú ý không để dung dịch F- Decalin chui qua vết rách (nếu có) vào dưới võng mạc. Sau khi võng mạc được trải và cố định dưới dung dịch $\mathrm{F}$-Decalin, tiến hành bóc màng tăng sinh sơ giải phóng co kéo trước-sau và co kéo tiếp tuyến, cắt sạch dịch kính còn sót lại và hút dịch dưới võng mạc qua vết rách VM (nếu có) hoặc mở VM ngoại vi. Sau đó tiến hành laser bao quanh vết rách, laser quang đông toàn võng mạc, trao đổi khí dịch với áp lực khí $30 \mathrm{mmHg}$, cuối cùng là thì hút sạch dung dịch $\mathrm{F}$-Decalin và đóng vết mổ kèm theo bơm 0,5 đến $0,7 \mathrm{ml}$ khí nở $\mathrm{C}_{3} \mathrm{~F}_{8}$ hoặc dầu silicone.

Đánh giá sau phẫu thuât :Bênh nhân sau phẫu thuật bơm khí hoặc dầu silicone phải nằm sấp 7-14 ngày đầu. Trong những ngày nằm viện bệnh nhân được theo dỗi các diễn biến về thị lực, nhãn áp, tình trạng võng mạc và các biến chứng có thể xảy ra như xuất huyết tiền phòng, xuất huyết dịch kính, tăng nhãn áp...Sau khi ổn định bệnh nhân được ra viện và tái khám định kỳ sau 1 tuần, 1 tháng và 3 tháng. Các chỉ tiêu đánh giá mối lần khám lại:

- Thị lực nhìn xa có và không chỉnh kính, nhãn áp đo bằng nhãn áp kế Goldmann

- Khám sinh hiển vi đánh giá bán phần trước, tình trang võng mạc áp sau phẫu thuật

- Từ lần khám sau 1 tháng trở đi bệnh nhân sẽ được làm thêm chụp OCT hoàng điểm.

\section{KẾT QUẢ NGHIÊN CỨU VÀ BÀN LUÂN}

1. Đặc điểm đối tượng nghiên cứu. Trong 21 bệnh nhân nghiên cứu có 16 nam 
chiếm 76,2\%, nữ là 5 bệnh nhân chiếm 23,8\%. Tuổi trung bình của nhóm nghiên cứu là $58,9 \pm 12,7$, trong đó độ tuổi $<40$ tương ứng với những bệnh nhân mắc ĐTĐ typ 1 có 3 bệnh nhân (14,3\%), độ tuổi $\geq 40$ tương ứng với nhóm bệnh nhân ĐTĐ typ 2 có 18 bệnh nhân $(85,7 \%)$. Thời gian phát hiện ĐTÐ trung bình $12 \pm 4$ năm, chủ yếu là nhóm bệnh nhân có thời gian phát hiện $Đ T Ð \geq 10$ năm với 15 bệnh nhân $(71,4 \%)$, nhóm < 10 năm có 6 bệnh nhẩn $(28,6 \%)$.

\section{Kết quả phẫu thuâtt}

Kết quả về mặt giải phẫu: bệnh nhân có tình trạng võng mạc áp tốt tại thời điểm ra viện và khám lại sau 1 tuần là $100 \%$. Tại thời điểm 1 tháng, tỷ lệ bệnh nhân có tình trạng võng mạc áp tốt là $85,7 \%$ (18/21), võng mạc không áp là
14,3\% (3/21). Có 3 bệnh nhân BVM một phần tại thời điểm 1 tháng, trong đó có 2 bệnh nhân còn dịch dưới võng mạc phát hiện qua soi đáy mắt và trên phim chụp $O C T, 1$ bệnh nhân bong võng mạc cao do xuất hiện vết rách thứ phát. Bệnh nhân này đã được phẫu thuật cắt dịch kính và bơm dầu silicon nội nhãn, tiếp tục theo dõi sau 3 tháng. Tại thời điểm 3 tháng, tỷ lệ võng mạc áp tốt 95,2\% (20/21), vẫn còn 1 trường hợp còn dịch dưới võng mạc $4,8 \%(1 / 21)$, nguyên nhân là võng mạc bong lâu ngày xơ hóa, dịch dưới võng mạc sau cần thời gian để hấp thu thông qua qua biểu mô sắc tố, chúng tôi không tiến hành can thiệp thêm. Tỳ lệ võng mạc áp thành công sau phẩu thuật tương tự với các tác giả ngoài nước cũng khá cao trên $85 \%^{3,4,5}$.

\section{Kêt quả về mặt thị lực:}

\begin{tabular}{|c|c|c|c|c|c|c|}
\hline Thị lực & $\begin{array}{c}\text { ST(+)- } \\
\text { ĐNT<1m }\end{array}$ & $\begin{array}{c}\text { ĐNT1m- } \\
\text { ĐNT<3m }\end{array}$ & $\begin{array}{c}\text { ĐNT3m- } \\
\mathbf{< N 2 0 / 2 0 0}\end{array}$ & $\begin{array}{c}\mathbf{2 0 / 2 0 0 -} \\
\mathbf{< 2 0 / 6 0}\end{array}$ & $\begin{array}{c}\mathbf{2} \\
\mathbf{2 0 / 6 0}\end{array}$ & Tổng \\
\hline Trước PT & $71,4 \%$ & $14,3 \%$ & $9,5 \%$ & $4,8 \%$ & 0 & $100 \%$ \\
\hline Sau PT 3 tháng & $23,8 \%$ & $28,6 \%$ & $33,3 \%$ & $9,5 \%$ & $4,8 \%$ & $100 \%$ \\
\hline
\end{tabular}

Đã có sự cải thiện đáng kể về thị lực tại thời điểm sau phẫu thuật 3 tháng so với trước khi phẫu thuật. Thị lực được quy đổi sang tham chiếu logMAR để đánh giá sự thay đổi chính xác nhất cho dù thị lực chỉ cải thiện được một hàng. Trước phẫu thuật đa phần bệnh nhân có thị lực rất thấp dưới ĐNT $5 \mathrm{~m}$. Thị lực trung bình trước phẫu thuâtt theo logMAR là $2,02 \pm 0,5$. Do sau khi cắt dịch kính điều trị BVM, bệnh nhân được bơm khí nở vào buồng dịch kính để làm áp võng mạc và tạo điều kiện cho quá trình viêm dính sẹo laser vết rách võng mạc, nên khi khám lại tại các thời điểm 1 tuần và 1 tháng sau phẫu thuật, sự thay đổi về mặt thị lực chưa có ý nghĩa do vẫn còn bóng khí. Chỉ ở thời điểm 3 tháng sau phẫu thuật, khi bóng khí nở hoàn toàn tiêu hết, thị lực bệnh nhân được cải thiện, với giá trị trung bình theo $\log M A R$ là $1,48 \pm 0,4$. Sự khác biệt này có ý nghĩa thống kê với $p<0,001$.

Biến chứng sau phẫu thuật: Theo nghiên cứu ghi nhận có 5 trường hợp xảy ra biến chứng trong quá trình theo dõi $(23,8 \%)$, và 16 trường hợp không xảy ra biến chứng (76,2\%). Trong đó:

- Biến chứng tăng nhãn áp xuất hiên trên 2 bệnh nhân ở thời điểm 2 ngày sau phẫu thuật. Thăm khám không thây có biểu hiện viêm bán phân trước, IOL và mống mắt hoàn toàn bình thường, võng mạc áp dưới bóng khí nở, soi góc tiền phòng mở và không có dính góc. Nguyên nhân có thể do tốc độ nở bóng khí nội nhãn vượt quá khả năng bù trừ của đường thoát thủy dịch.

- 2 trường hợp xuất huyết dịch kính không

cần phải phẫu thuật lại. Tỷ lệ xuất huyết dịch kính sau phẫu thuật BVM co kéo theo các báo cáo trước đây dao động từ 5 đến $55 \%{ }^{6,7,8}$. Xuất huyết dịch kính sau phẫu thuật thường gặp ở những trường hợp BVM co kéo phức tạp, cần đòi hỏi bóc tách các co kéo rộng gây tổn thương võng mạch cùng các mạch máu6,8, ngoài ra việc kiểm soát đường huyết kém cũng là yếu tố nguy cơ cao gây biến chứng này ${ }^{6}$. Xuất huyết có thể từ tân mạch còn sót lại, các mạch máu vỡ trong quá trình phẫu thuật, hoặc từ tẩn mạch mới xuất hiện ${ }^{8}$. Chúng tôi cho rằng việc tiêm Avastin trước phẫu thuật 5-7 ngày đã làm giảm đáng kể tỷ lệ biến chứng xuất huyết dịch kính sau mồ.

- 1 trường hợp xuất hiện màng trước võng mạc tại thời điểm 3 tháng sau phẩu thuật phát hiện trên phim chụp OCT, các yếu tố nguy cơ hình thành màng trước võng mạc như màng $x$ ơ mạch, màng dịch kính sau bám chắc vào võng mạc không thể bóc tách hoàn toàn trong quá trình phẫu thuật, xuất huyết dịch kính sau phẫu thuật ${ }^{9}$. Đây cũng là 1 nguyên nhân khiến thị lực bệnh nhân không cải thiện sau phẫu thuật.

- Ngoài ra các biến chứng khác các đề cập đến trong y văn như: còn sót $P F C L$ nội nhãn, bong hắc mạc, glôcôm tân mạch hay teo nhãn cầu chúng tổi không gặp ở các trường hợp trong nghiên cứu này 3,5 ,

3. Các yếu tố liên quan đến kết quả phẫu thuật

Mức độ bong vông mạc liên quan đến kêt quả giải phầu: 


\begin{tabular}{|c|c|c|c|}
\hline $\begin{array}{c}\text { Tình trạng VM } \\
\text { Mức độ bong }\end{array}$ & $\begin{array}{c}\text { Võng } \\
\text { mạc áp } \\
\text { tốt }\end{array}$ & $\begin{array}{c}\text { Võng } \\
\text { maac } \\
\text { khống áp }\end{array}$ & Tổng \\
\hline Chưa qua hoàng điếm & $92,9 \%$ & $7,1 \%$ & $100 \%$ \\
\hline Qua hoàng điếm & $71,4 \%$ & $28,6 \%$ & $100 \%$ \\
\hline Tống & $\mathbf{8 5 , 7 \%}$ & $\mathbf{1 4 , 3 \%}$ & $\mathbf{1 0 0} \%$ \\
\hline
\end{tabular}

Tỷ lệ võng mạc áp tốt ở nhóm chưa bong qua hoàng điểm là $92,9 \%$. Ở nhóm bong qua hoàng điểm tỷ lệ này là $71,4 \%$. Tỷ lệ thành công thấp hơn theo nhiêu nghiên cứu cho rằng do võng mạc bong lâu ngày quá trình xơ hóa của võng mạc làm cho võng mạc khó áp lại sau mổ.

Mức độ bong võng mạc liên quan đến kết quả thị lực:
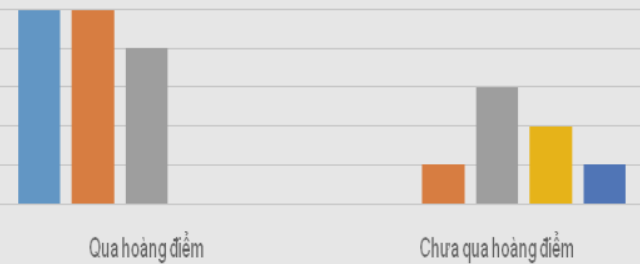

IST $++\mid-<\theta N T 1 m \quad\|\theta N T 1 m-<\theta N T 3 m \quad\| \theta N T 3 m-<20 / 200 \quad \| 20 / 200-20 / 60 \quad$ \} \geq 2 0 / 6 0

Thị lực theo các nhóm được quy ra giá trị log Mar

\begin{tabular}{|c|c|c|}
\hline $\begin{array}{c}\text { Mức độ bong } \\
\text { võng mạc }\end{array}$ & $\begin{array}{c}\text { Bong qua } \\
\text { hoàng điểm }\end{array}$ & $\begin{array}{c}\text { Bong chưa qua } \\
\text { hoàng điểm }\end{array}$ \\
\hline $\begin{array}{c}\text { Thị lực trung bình } \\
\text { theo logMAR }\end{array}$ & $1,68 \pm 0,3$ & $1,09 \pm 0,3$ \\
\hline
\end{tabular}

Sự khác biệt về thị lực của nhóm BVM qua hoàng điểm và chưa qua hoàng điểm có ý nghĩa thống kê với $p<0,05$. Hoàng điểm tập chung nhiều tế bào nón, đảm đương chức năng thị giác cao nhất và chức năng sắc giác, BVM qua hoàng điểm là một biến chứng nặng, đe dọa thị lực trầm trọng, cho dù kết quả giải phẫu tốt nhưng quá trình bong lâu ngày khiến võng mạc vùng hoàng điểm không được nuôi dưỡng, sự chết dần của các tế bào quang cảm thụ ánh sáng dẫn đến kết quả thị lực phục hồi kém.

Diện tích màng tăng sinh co kéo võng mạc liên quan kết quả giải phẫu :

Tinh trạng vông mạc theo các nhóm

\begin{tabular}{|c|c|c|c|}
\begin{tabular}{|c|c|} 
Tình trạng VM \\
Diện tî́ch màng \\
tang sinh
\end{tabular} & $\begin{array}{c}\text { Võng } \\
\text { mác áp } \\
\text { tốt }\end{array}$ & $\begin{array}{c}\text { Võng } \\
\text { mạc } \\
\text { không áp }\end{array}$ & Tổng \\
\hline$<2$ cung phần tư' & $100 \%$ & $0 \%$ & $100 \%$ \\
\hline $\begin{array}{c}<=2 \text { cung phần } \\
\text { tứ }\end{array}$ & $72,7 \%$ & $27,3 \%$ & $100 \%$ \\
\hline Tống & $\mathbf{8 5 , 7 \%}$ & $\mathbf{1 4 , 3 \%}$ & $\mathbf{1 0 0 \%}$ \\
\hline
\end{tabular}

Tất cả những bệnh nhân có diện tích màng tăng sinh co kéo võng mạc dưới 2 cung phần tư trở xuống đều có kết quả giải phẫu võng mạc áp tốt ở các thời điểm khám lại sau 1 tháng và 3 tháng. Ở nhóm diện tích màng tăng sinh từ 2 cung phần tư trở lên, $72,7 \%$ bệnh nhân có võng mạc áp tốt sau phẫu thuật, $27,3 \%$ bệnh nhân còn bong võng mạc. Sự khác biệt giữa 2 nhóm bệnh nhân có diện tích màng tăng sinh co kéo võ̉ng mạc trên và dưới 2 cung phần tư có ý nghĩa thống kê với $\mathrm{p}<0,05$. Nhóm bệnh nhân diện tích màng tăng sinh dưới 2 cung phần tư có kểt quả võng mạc áp tốt hơn nhóm từ 2 cung phần tư trở lên. Kết quả này là hợp lý do quá trình bóc tách màng tăng sinh rộng, giải phóng co kéo võng mạc, thậm chí phải cắt 1 phần võng mạc gây ra các tổn thương trên võng mạc, tăng tỉ lệ xuất hiện các vết rách thứ phát, có thể bỏ sót trong phẫu thuật. Ngoài ra bản thân với màng tăng sinh rộng cũng khó bóc tách triệt để, màng còn sót lại gây ra các co kéo thứ phát, làm võng mạc khó áp trở lại hơn.

Tình trạng bong dịch kính sau liên quan đến kết quả giải phấu:

\begin{tabular}{|c|c|c|c|}
\hline $\begin{array}{r}\text { Tình trạng võng } \\
\text { mạc } \\
\text { Tình trạng } \\
\text { bongdịch kính saut }\end{array}$ & $\begin{array}{c}\text { Võng } \\
\text { mác áp } \\
\text { tốt }\end{array}$ & $\begin{array}{c}\text { Võng } \\
\text { mạc } \\
\text { khống } \\
\text { áp }\end{array}$ & Tổng \\
\hline Bong một phần & $80 \%$ & $20 \%$ & $100 \%$ \\
\hline Bong hoàn toàn & $100 \%$ & 0 & $100 \%$ \\
\hline Tống & $85,7 \%$ & $14,3 \%$ & $100 \%$ \\
\hline
\end{tabular}

Tất cả những bênh nhân bong dịch kính sau hoàn toàn cho kết quả võng mạc áp tốt $100 \%$ sau khám lại. ở nhóm bênh nhân bong dịch kính sau 1 phần hoặc chưa bong dịch kính sau tỷ lệ này là $80 \%$. Sự khác biệt giữa 2 nhóm này có ý nghĩa thống kề $\mathrm{p}<0,05$. Trong phẫu thuật cắt dich kính, dịch kính sau chưa bong hoăc bong không hoàn toàn là một thách thức. Nguy cơ sót dịch kính trong quá trình phẫu thuật rất cao, tạo điều kiện cho tăng sinh dịch kính võng mạc sau phẫu thuật, BVM tái phát, các tăng sinh trước hoặc dưới võng co kéo mạc khiến võng mạc khó áp trở lại hơn.

Tình trạng bong dịch kính sau liên quan đên kêt quả thị lực

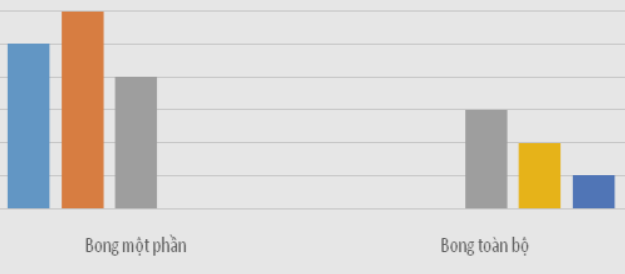

แ $S T(+)-<\ominus N T 1 m \quad\|\ominus N T 1 m-<\ominus N T 3 m \quad\| \ominus N T 3 m-<20 / 200 \quad\|20 / 200-20 / 60 \quad\| \geq 20 / 60$ 
Thi lức trung binh của hai nhóm theo $\log M A R$

\begin{tabular}{|c|c|c|}
\hline $\begin{array}{c}\text { Tình trạng dịch } \\
\text { kính sau }\end{array}$ & $\begin{array}{c}\text { Bong } \\
\text { toàn bộ }\end{array}$ & $\begin{array}{c}\text { Bong 1 } \\
\text { phần }\end{array}$ \\
\hline $\begin{array}{c}\text { Thị lực trung bình } \\
\text { theo logMAR }\end{array}$ & $\begin{array}{c}1,67 \pm \\
0,3\end{array}$ & $1,02 \pm 0,3$ \\
\hline
\end{tabular}

Sự khác biệt về thị lực của 2 nhóm là có ý nghĩa thống kể với $p=0,001<0,05$. Khi dịch kính sau còn sót lại, tạo điêu kiện cho tăng sinh dịch kính võng mạc sau phẫu thuật và kết quả có thể tạo thành màng trước võng mạc, tăng sinh trước và dưới võng mạc, võng mạc khó áp trở lại. Thị lực tiên lượng ở nhóm này sẽ thấp hơn nhóm có bong dịch kính sau hoàn toàn.

Chất độn nội nhãn liên quan đến kêt quả giải phấu:

\begin{tabular}{|c|c|c|c|}
$\begin{array}{c}\text { Tình trạng } \\
\text { vãng mạc } \\
\text { Chất đợn } \\
\text { nội nhãn }\end{array}$ & $\begin{array}{c}\text { võng } \\
\text { mạc áp } \\
\text { tốt }\end{array}$ & $\begin{array}{c}\text { Võng mác } \\
\text { không áp }\end{array}$ & Tổng \\
\hline C3F8 & $92,9 \%$ & $7,1 \%$ & $100 \%$ \\
\hline Dầu Silicon & $71,4 \%$ & $28,6 \%$ & $100 \%$ \\
\hline Tổng & $85,7 \%$ & $14,3 \%$ & $100 \%$ \\
\hline
\end{tabular}

Bệnh nhân sử dụng khí C3F8 cho kết quả võng mạc áp tốt $92,9 \%$ sau khám lại 1 và 3 tháng. Ở nhóm bệnh nhân sử dụng dầu silicon tỷ lệ này là $71,4 \%, 28,6 \%$ võng mạc không áp. Tỷ lệ võng mạc áp thấp hợn tại nhóm sử dụng dầu Silicon có thể giải thích do dầu Silicon thường được sử dụng trong các trường hợp co kéo võng mạc phức tạp mà phẫu thuật khổng thể loại bỏ hoàn toàn được, cần chèn ép lâu dài tạo điều kiện cho võng mạc áp trở lại; hoặc những trường hợp kèm theo rách võng mạc phía dưới, bệnh nhân khó khăn trong việc duy trì tư thế sau phẫu thuật. Sức căng bề mặt của khí/nước cao hơn so với dầu silicon/nước (70erg/cm2 so với 50 erg/cm2), điều này cũng lý giải được tỷ lệ thành công của khí nở C3F8 luôn cao hơn dầu silicon ${ }^{8,9}$.

Chất độn nội nhãn liên quan đến kêt quả thị lực:

\begin{tabular}{|c|c|c|}
\hline Chất độn & C3F8 & Dâu Silicon \\
\hline $\begin{array}{c}\text { Thị lực trung } \\
\text { bình (logMAR) }\end{array}$ & $1,26 \pm 0,3$ & $1,91 \pm 0,15$ \\
\hline
\end{tabular}

Sự khác biệt về thị lực của 2 nhóm này là có ý nghĩa thống kê với $P<0,05$. Theo $y$ văn dầu Silicon nội nhãn là 1 yếu tố nguy cơ dẫn đến việc thị lực phục hồi kèm sau phẫu thuật với bệnh nhân bị bệnh võng mạc đái tháo đường ${ }^{8}$. Bên cạnh việc sử dụng dâuu silicon cho những trường hợp bong võng mạc phức tạp, thị lực kém trước mổ thì dâuu silicon còn liên quan đến sự mỏng đi của các lớp võng mạc vùng hoàng điểm trên $\mathrm{OCT}^{9}$.

\section{KẾT LUẬN}

Phẫu thuật cắt dịch kính có sử dụng dung dịch PFCL điều trị BVMco kéo do bệnh võng mạc ĐTĐ là kỹ thuật rất phức tạp, nhằm phục hồi giải phẫu và một phần thị lực cho bệnh nhân. Mặc dù thị lực cải thiện không cao vì nằm trong bệnh cảnh nặng nề chungcủa bệnh võng mạc ĐTÐ giai đoạn muộn. Với kỹ thuật và trang thiết bị được cải thiện, khả năng phục hồi về chức năng và giải phẫu đã có nhiêu hứa hẹn. Tuy nhiên, vẫn cần phải nhắc lại là việc sàng lọc và phát hiện sớm bệnh võng mac ĐTĐ có ý nghĩa rất lớn trong cộng đồng, mà kết quả là giảm thiểu số ca mắc bệnh giai đoạn muộn.

\section{TÀI LIÊU THAM KHẢO}

1. Haidt SJ, Clark LC, Ginsberg J. Liquid perfluorocarbon replacement in the eye.Invest Ophthalmol Vis Sci,.Published online 1982:22.

2. Chang $S$, Ozmert E, Zimmerman NJ. Intraoperative perfluorocarbon liquids in the management of proliferative vitreoretinopathy.Am J Ophthalmol. 1988;106(6):668-674. doi: 10.1016/ 0002-9394 (88)90698-8

3. Arevalo JF, Serrano MA, Arias JD. Perfluorocarbon in vitreoretinal surgery and preoperative bevacizumab in diabetic tractional retinal detachment. World J Diabetes. 2014;5(5): 724-729. doi:10.4239/wjd.v5.i5.724

4. Imamura $\mathbf{Y}$. Use of perfluorocarbon liquid during vitrectomy for severe proliferative diabetic retinopathy. British Journal of Ophthalmology. 2003;87(5):563-566. doi:10.1136/bjo.87.5.563

5. Sato T, Tsuboi K, Nakashima H, Emi K. Characteristics of cases with postoperative vitreous hemorrhage after 25-gauge vitrectomy for repair of proliferative diabetic retinopathy. Graefes Arch Clin Exp Ophthalmol. 2017;255(4):665-671. doi:10.1007/s00417-016-3522-8

6. Yang C-M, Yeh P-T, Yang C-H. Intravitreal longacting gas in the prevention of early postoperative vitreous hemorrhage in diabetic vitrectomy. Ophthalmology. 2007;114(4):710-715. doi: 10.1016/ j.ophtha.2006.07.047

7. Meleth AD, Carvounis PE. Outcomes of vitrectomy for tractional retinal detachment in diabetic retinopathy.Int Ophthalmol Clin. 2014;54(2):127-139.

doi:10.1097/IIO.0000000000000021

8. Yorston D, Wickham $L$, Benson S, Bunce $C$, Sheard R, Charteris D. Predictive clinical features and outcomes of vitrectomy for proliferative diabetic retinopathy. $\mathrm{Br} \mathrm{J}$ Ophthalmol. 2008;92(3):365-368. doi:10.1136/bjo.2007.124495

9. Christensen UC, la Cour M. Visual loss after use of intraocular silicone oil associated with thinning of inner retinal layers. Acta Ophthalmol. 2012; 90(8): 733-737. doi:10.1111/ j.1755-3768. 2011.02248.x 